\title{
Surgical management of major Vascular Injuries during Abdominal pelvic Surgery: - How I do? - A series of 15 cases
}

\author{
Dr. Vinay Naithani \\ Professor and Head, Department of Cardio Thoracic and Vascular Surgery \\ RNT Medical College and MB Government Hospital, Udaipur, Rajasthan, India
}

\begin{abstract}
Aim and objectives: To evaluate simple manoeuvres and techniques to control catastrophic bleeding from major abdomino-pelvic major vessels.

Material and methods: This study was conducted between 2003 to 2013. A total of 15 cases were considered in this study. Patients had iatrogenic injuries during dissection or were diagnosed during operation, as sudden gush of profuse bleeding started in trauma patients. Simple indigenous techniques and manoeuvres are discussed to save life of patients, when operating room is not ready to deal with such surprising catastrophic events.
\end{abstract}

Results: Bleeding was controlled effectively in all patients. All patients required ventilator and inotropic supports. We had one mortality. Remaining 14 patients did well and discharge on 13-18 days postoperatively.

Conclusion: Simple manoeuvres and techniques to control catastrophic bleeding from major abdomino- pelvic major vessels are effective in emergency situations.

Keywords: Major vascular injuries, Abdomino-pelvic surgery, IVC injury, Aorta injury, Portal vein injury

\section{Introduction}

Management of Torrential bleeding from major vessels are still a challenge to all surgeons. This situation worsens if this has to be managing with limited instrumentation and technical assistance mainly in unexpected situation. Simple manoeuvres and techniques, Patience, and assurance to colleagues usually help in managing these catastrophes.

\section{Material, Methods and results}

This study was conducted in Department of Cardio Thoracic and Vascular surgery, RNT Medical College, Udaipur. We present a series of 15 patients where we were called directly in operation theatre for management of torrential bleeding from major abdomino-pelvic vessels. We managed 10 patients $(66.67 \%)$ from Department of General surgery and five patients (33.33\%) from Department of gynaecology. When we were called Patients were in severe shock. Colloid, crystalloid and blood transfusion has already been started.

Patients were on heavy inotropic supports. There was chaos and apprehension on every face due continuous pool of blood with no proper visualisation of bleeding vessel. Blind efforts have further worsened the situation.

To control any significant bleeding we need -

Proper light

Proper visualisation of bleeding vessel

Manoeuvres and techniques to reduce bleeding

Proximal and distal control

Proper instrumentation

Avoid blind suturing and efforts (figure 1)

Have Confidence and patience

Boost moral support of assistants and nursing 


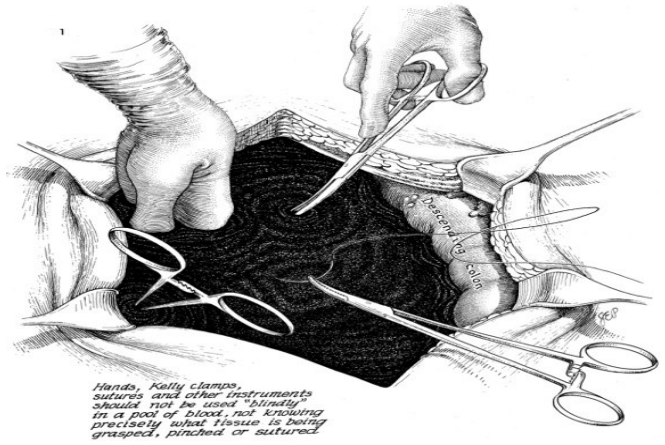

Figure 1

Case 1

A 60 year old female patient was operated for cholecystectomy and due to dense adhesion all around during dissection there was portal vein injury. The blood started exsanguinating, causing poor visibility. We were called in operation theatre. By that time patient was in severe hypotension and was on heavy inotropic support. When we saw the wound, packing and compression was applied over it. I asked Nursing assistant to be ready with 4/0 R/B polypropylene suture and instructed him to load suture again and again during repairing vessel. I instructed assistants don't afraid of bleeding vessel ,we will definitely control bleeding . We removed packs and ask assistant to pinch the vessel between thumb and index finger proximally at foramen of Winslow. I kept a firm pressure with small gauze distally to reduce back flow (Figure 1). Bleeding has significantly reduced and I could able to see site with help of strong suction. As my one hand was engaged in pinching the vessel I took help of my nursing colleague to load suture again and again. Once I reached to last corner of wound, I disengaged my hand (which was compressing distal vessel) and started pulling the suture with this hand.

Overrunning over the previous suture line and tying knot, the problem which seems to be terrible was over. Wound closed. Patient shifted to ICU, kept on inotropic and elective ventilation for twelve hours. Patient extubated and inotropic weans off slowly within 24 hours, and patient did well.

\section{Case 2}

A 46 year old woman explored for CBD stone. During dissection there was injury to portal vein. I pressed distal vein with index finger and asked assistant to pinched proximal portal vein at foramen of Winslow Bleeding reduced and Injury site repair similarly as mention above with 4-0 Polypropylene suture. Bleeding stopped and patient did well.

\section{Case 3}

A 55 year old lady underwent cholecystectomy with CBD stone exploration. There was dense adhesion all around. While dissecting there was profuse venous bleeding and found to have portal vein injury Unsuccessful attempts to repair by operating surgeon has worsen the situation. Patient was in severe shock and on heavy inotropic support. Our entire attempt failed and we lose the patient.

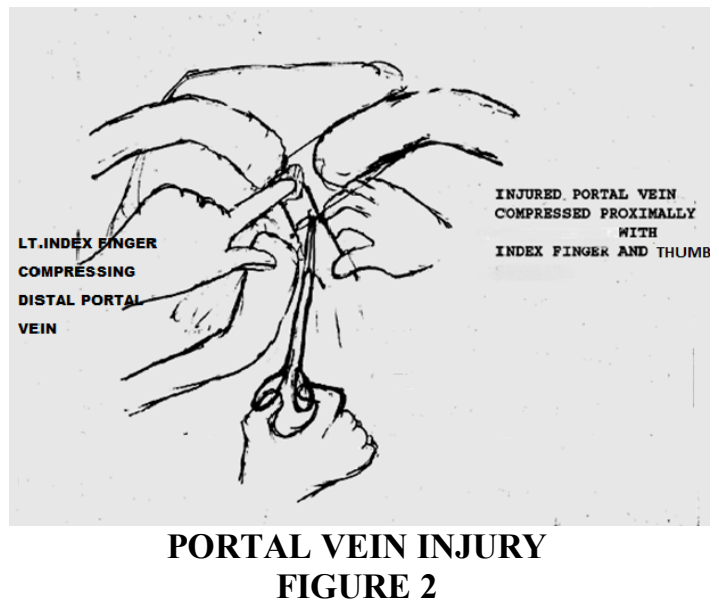

\section{CASE 4}

A 35 year old female was operated for Wertheim's hysterectomy and while dissecting lymph nodes on right side of vertebral bodies IVC was torn. There was torrential bleeding and lack of visibility. Exsanguination 
of blood has precipitated hypotension. When we assessed, patient was in severe shock and was on heavy inotropes, wound was packed all around. We retracted bowl loops first and then removed packs from the bleeding site. I just kept widen middle and index finger firmly around tear to occlude IVC against vertebral body. This manoeuvre has stopped bleeding to a good extend (as venous pressure is less) (Figure 2). I took a bite of 4/0 R/B polypropylene suture from one corner and all time took help of assistant to load the suture (as one of my hand was engage in compressing IVC). Once I reached to another side of wound simply pulling suture with one hand (which was previously pressing IVC) bleeding has stopped. Another layer of over run suture was taken and knot tied. Bleeding stopped and blood pressure regained with Fluid and blood transfusion. Inotropes has reduced to moderate level now. Patient kept on ventilator, shifted to ICU, extubated and did well postoperatively

\section{Case 5}

An 18 yrs boy had blunt injury abdomen with injury RT. Kidney and liver. On exploration we found multiple lacerations liver and retro peritoneal hematoma. Liver lacerations repaired while handling injured RT. Kidney it was found to have avulsion of hilum and IVC tear. IVC repaired in similar fashion as above Rt. Nepherectomy performed. Pt. did well.

\section{Case 6}

A 20 yrs boy had penetrating injury abdomen by knife. Patient was assessed and explore for ileal perforation. After repair, while looking for other injuries, there was profuse venous bleeding. We were called and we found IVC tear near RT infrarenal region. We repair it as mention above.

\section{Case 7}

A 22 year old male was operated in emergency for stab injury with ileal perforation. After closure of ileal perforation and while retracting bowl loops vigorously, there was profuse venous bleeding from IVC tear which was previously hidden by Haematoma and clot. When we were called, we removed packs and with pressure with index and middle finger around tear site, we could able to control bleeding. Sutures was taken with help of $4 / 0$ polypropylene suture. Bleeding stopped abdomen closed patient shifted to ICU inotropes weans off and patient did well postoperatively

\section{Case 8}

A50 year old male, diagnosed as case of RT. kidney malignancy. Patient was operated for RT. Radical nephrectomy. During excision of mass there was IVC tear. We repair it as mention above.

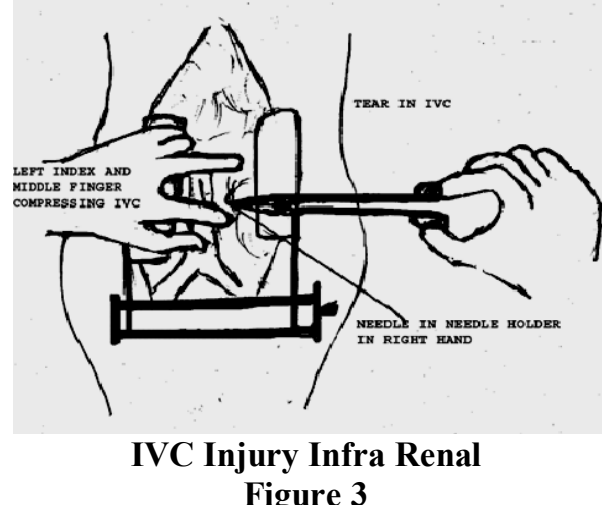

\section{Case 9}

A 26 year old female patient operated for cholecystectomy with CBD stone. As there were dense adhesion, during dissection there was injury to IVC causing profuse bleeding and no visibility. Patient went into severe shock, heavy inotropes started. When we assessed, there was compressive packing all around. Incision was extended vertically and subcoastel incision became " $\mathrm{T}$ " shaped to increase visibility. Assistant was instructed to be ready with $4 / 0$ polypropylene suture. Then packing pads removed one by one. As it was deep I took help of sponge on sponge holder to press the distal end, I pressed proximal end with my index finger and thumb. Visibility was clear and I started closing rent in IVC with 4/0 polypropylene suture. All the time loading of needle was done by assistant. Bleeding stopped and wound closed. Patient shifted to ICU kept on ventilator and extubated. Inotropes withdrawn within $24 \mathrm{hrs}$ and patient did well postoperatively 


\section{Case 10}

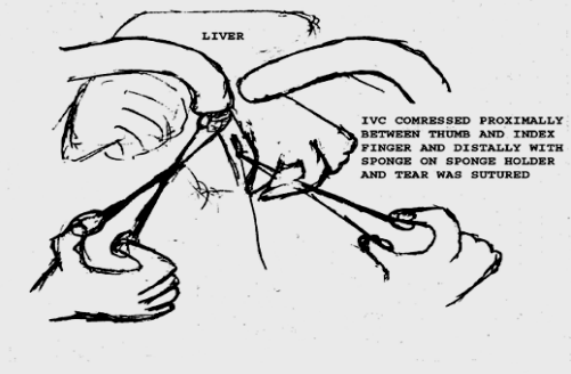

Ivc Injury Surarenal

Figure 4

A 40 year old female was operated for large adherent malignant ovarian tumour. While dissecting last part of it, there was profuse bright coloured pulsatile bleeding. Attempts made to suture it but suture cut through, which aggravated bleeding and hypotension. There was bleeding from aorta bifurcation medial aspect. Packing done, heavy inotropes started to maintain blood pressure. When we were called we did not touch the site but aorta was first Blalock looped around proximally and tightened. With index and thumb pressure distally, bleeding was considerably reduced. Suturing with 4/0 polypropylene round body from one end and following suture tightly by assistant bleeding has reduced and overrun second layer has stopped the bleeding. Inotropes reduced to moderate level, shifted to ICU, electively ventilated for 4 hours, extubated and did well postoperatively.

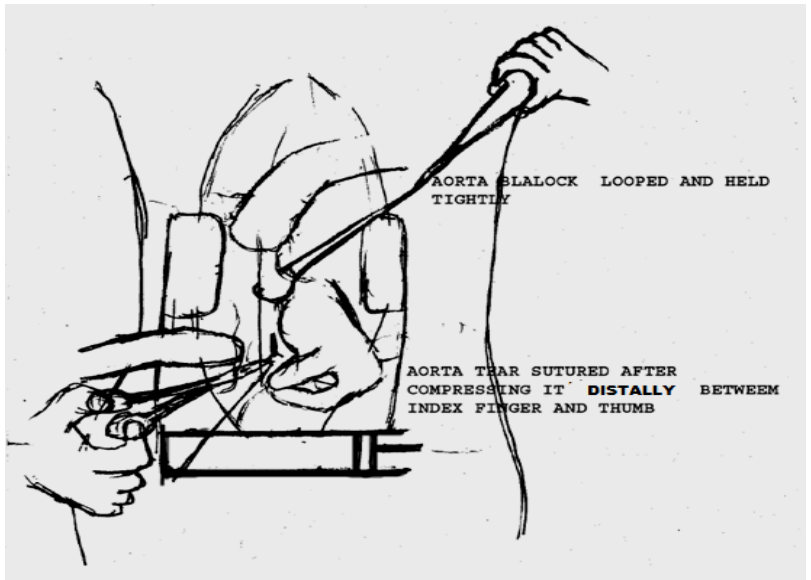

Figure 5

\section{Case 11}

A 52 year old female operated for malignant ovarian tumour. While dissecting on left side there was profuse bleeding from left common iliac vein attempts tried but failed, by that time patient went into hypotension and inotropes started. When we saw there was compressive packing. Packs removed and we took help of large sponge on sponge holder to occlude distal site against pelvic bone. Further proximal occlusion with middle and index finger pressure has improved visibility. Sutures taken with loading of suture with help of assistant. Bleeding stopped abdomen closed patient shifted to ICU. Inotropes weans off and patient did well postoperatively.

\section{Case 12}

A 24-year-old female with postpartum haemorrhage was operated for bilateral internal iliac ligation to reduce bleeding pervaginum and while dissecting on left side there was profuse venous bleeding from left common iliac vein. As patient was in shock, inotropes started, fluid and blood given. We removed pack and pressed with sponge on sponge holding forceps distally and proximally with index-middle finger pressure.

Visibility was improved and suturing done with help of assistant to load the suture repeatedly. Bleeding stopped, patient shifted to ICU inotropes weans off and patient did well postoperatively. 


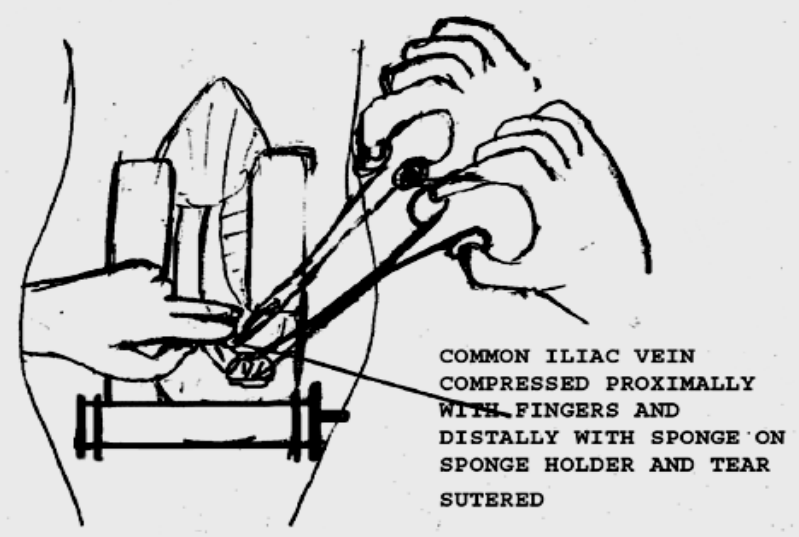

\section{Case 13}

Figure 6

A 35-year-old female patient was operated for huge ovarian mass. While dissecting on right side injury to common iliac artery occur. There was profuse bleeding. We removed pack, pinch the tear site of vessel between index finger and thumb of left hand, and closed the tear with help of assistant loading the suture all time. Tumour removed abdomen closed patient shifted to ICU inotropes weans off and patient did well postoperatively.

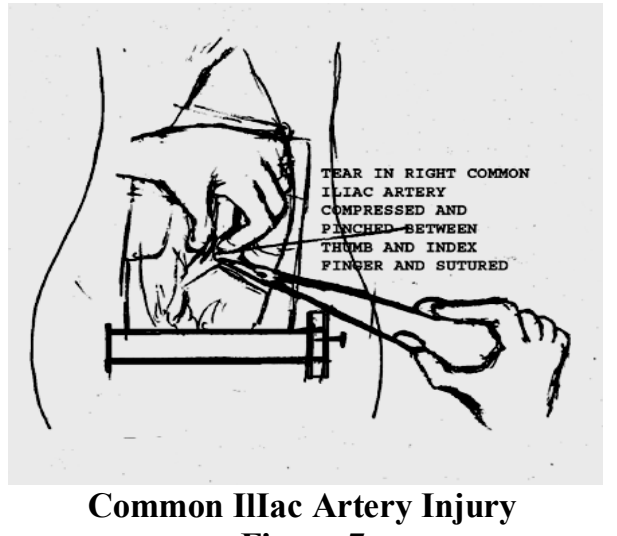

Figure 7

\section{Case 14}

A 40 year female patient with past history of Koch's chest came with came with swelling right inguinal region and diagnosed as psoas abscess. Incision and drainage done, pus came out on further opening the cavity there was profuse bright red colour bleeding. Patient was on mild inotropic support without spending time in exploring inguinal wound we did laprotomy and Blalock looped the aorta and pulled. As the blood, still coming out we Blalock looped both common iliac arteries. The bleeding has significantly reduced. On dissecting complete aortoiliac bifurcation, we found vertebral erosion and roughening and aortic erosion posterior wall due to potts spine. We pinched the site and took suture with 4-0 polypropylene suture and bleeding controlled. Patient did well postoperatively. 


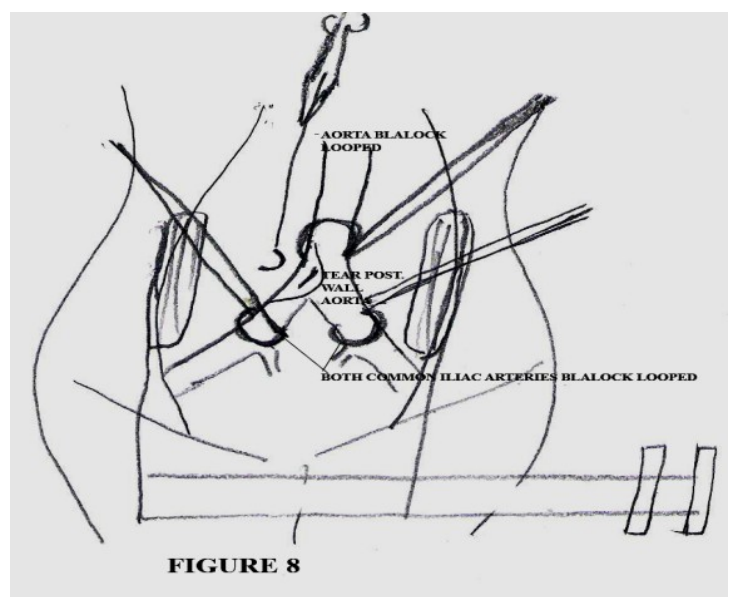

Aorta Posterior Wall at Bifurcation Tear

\section{Case 15}

A 25 year old boy had stab injury abdomen with ileal perforation and injury to diaphragm and liver. During mobilising liver by dividing ligaments there was profuse venous bleeding. We were called we extended incision to right lateral thoracotomy and found there was through rent at dome of diaphragm extending to IVCRA junction. We pinched the site between index finger and thumb, and taken continuous suture with 4-0 polypropylene. Bleeding stopped, liver rent repaired and closure done. Patient did well postoperative.

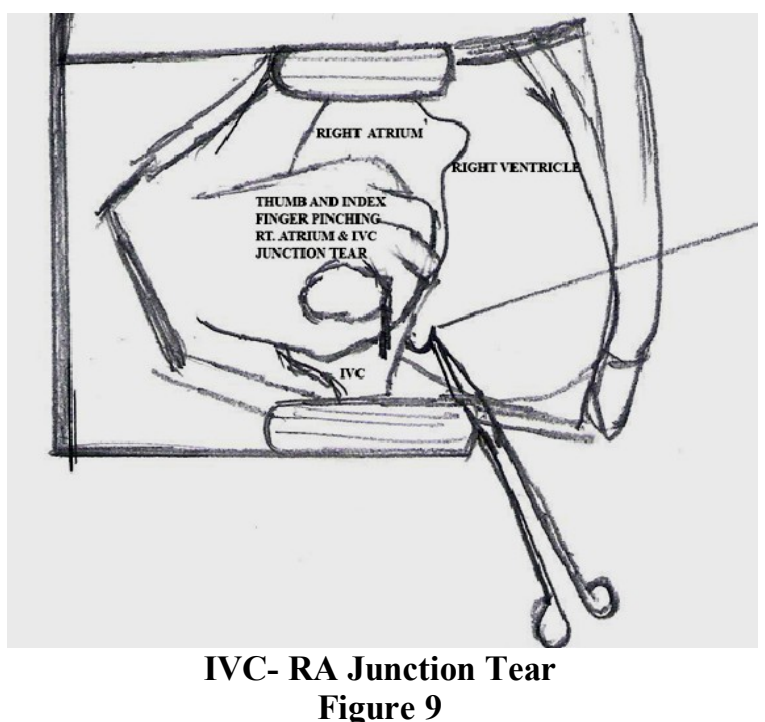

\section{Discussion}

Severe bleeding during major surgeries are discussed to a large extend in literature. Operative injuries of abdominal and pelvic major vessels occur in patients undergoing oncologic resection, difficult anatomic exposure, previous operation, recurrent tumour, and radiation therapy. Massive blood loss, acidosis, hypotension, and hypothermia are associated with increased risk for death. ${ }^{(1)}$

Iatrogenic major vascular injuries are though rare but used to happen even with utmost precaution of operating surgeon, and because of technical difficulties and inexperience of vascular surgery they lose their hope and it may be a curse for patient, the frequencies per 10000 operations were: after laparoscopy 0.93 , after laparotomies 0.76 and after major vaginal surgery, 0.33. Injuries during laparotomy were most frequently venous and all patients had haemorrhage as the main symptom ${ }^{(2)}$

Depending on the cause of injury, the mortality rate in these situations is extremely high if vascular surgeon is not standby. The mortality rate associated with major vessel injury if proper repair by vascular surgeon has been performed, reported to range from $8 \%$ to $17 \%{ }^{(3-6)}$ Iatrogenic vein injuries occur during radical surgery for cancers are associated with high morbidity and mortality as a result of massive bleeding. Rapid vascular control and venous repair improve early and late outcome. ${ }^{(7)}$

Serious complications can be minimized by immediate recognition and prompt repair of iatrogenic vascular injuries. Close collaboration with a vascular surgeon during resection of tumours in proximity to the 
vascular structures may be helpful in preventing iatrogenic vascular injuries. In hospitals where tumour resection procedures are frequently performed, a vascular surgeon must be readily available. ${ }^{(8)}$ With the increasing use of pelvic node dissection for staging and treating pelvic urological cancer, injury to the common, external and internal iliac veins will occur. ${ }^{(9)}$

Vascular injuries represent an utmost important intraoperative risk in the course of lymph node dissection in gynaecological malignancies. Thus, gynaecological surgeons performing radical operations must be prepared to deal with the problem. ${ }^{(10)}$

Bleeding control be achieved by packing, direct surgical bleeding control, and the use of local haemostatic procedures. In the exsanguinating patient, aortic cross clamping may be employed as an adjunct to achieve bleeding control. ${ }^{(11)}$

Most injuries were treated by direct suture repair. Arterial repair was accomplished by polytetrafluoroethylene (PTFE) interposition, PTFE patch angioplasty, resection and primary anastomosis, and ligation. The venous injury was repaired by lateral venorrhaphy. With immediate recognition, recovery was the rule. $^{(12)}$

However, when the source of bleeding is intra-abdominal, thoracic aortic clamping combined with other measures for haemorrhage control can be life-salvaging in nearly one third of patients. Compare thoracic aortic clamping above the diaphragm with abdominal aortic clamping just below the diaphragm; some surgeons favor the latter method. The cross-clamping of the aorta should be considered as an adjunct to other initial hemorrhage control measures such as the evacuation of blood, direct surgical bleeding control, or packing of bleeding sources. When aortic clamping is deemed necessary due to continuous bleeding or low blood pressure, the prognosis is generally poor.$^{(11)}$

Treatment of the abdominal tumours closely related to major blood vessels must be interdisciplinary, considering diagnostics, operability estimation and additional measures. Tumour reduction cannot improve long term prognosis, and has no major impact on life quality. ${ }^{(13)}$

Conduction of training of general surgeons for the issues of emergent angiosurgery is necessary. ${ }^{(14)}$ Foleys catheter or Fogarty catheter insertion in bleeding vessel with balloon inflation helps in taking sutures bites but radiological interventions mainly helps in small vessel injuries.

\section{Conclusion}

Catastrophic vascular injuries can be avoided by proper vascular surgical training. In major oncologic resections, redo cases with dense adhesions and difficult anatomic exposure, presence of vascular surgeon helps in difficult situations. If major vascular injuries occurs calm atmosphere, proper exposure, control with Simple maneuvers and techniques even with limited instrumentation helps.

\section{References}

[1]. Oderich GS, Panneton JM, Hofer J, Bower TC, Cherry KJ Jr, Sullivan T, Noel AA, Kalra M, Gloviczki P. Iatrogenic operative injuries of abdominal and pelvic veins: a potentially lethal complication. J Vasc Surg. 2004 May; 39(5):931-6.

[2]. David Bergqvist and Agneta Bergqvist Vascular Injuries During Gynecologic Surgery Acta Obstetricia et Gynecologica Scandinavica, 1987, Vol. 66, No. 1 : Pages 19-23

[3]. Champault G, Cazacu F, Taffinder N. Serious trocar accidents in laparoscopic surgery: a French survey of 103,852 operations. Surg Laparosc Endosc. 1996;6(5):367-370. The risk of great vessel injury associated with laparoscopy most frequently quoted is 0.5 injuries for every 1,000 procedures.

[4]. Jansen F, Kapiteyn K, Trimbos-Kemper T, et al. Complications of laparoscopy: a prospective multicentre observational study. Br J Obstet Gynecol. 1997; 104(5):595-600.

[5]. Roviaro GC, Varoli F, Saguatti L, et al. Major vascular injuries in laparoscopic surgery. Surg Endosc. 2002; 16(8):1192-1196.

[6]. Wu MP, Lin YS, Chou CY. Major complications of operative gynecologic laparoscopy in Southern Taiwan. J Am Assoc Gynecol Laparosc. 2001;8(1):61-67.

[7]. Mandolfino T, Canciglia A, Taranto F, D'Alfonso M, Tonante A, Mamo M, Sturniolo G. Outcome of iatrogenic injuries to the abdominal and pelvic veins. Surg Today. 2008; 38(11):1009-12. Epub 2008 Oct 29.

[8]. Oktar GL Iatrogenic major venous injuries incurred during cancer surgery. Surg Today. 2007; 37(5):366-9. Epub 2007 Apr 30.

[9]. Dalton JR, Mulholland SG. Venous injury in major urological surgeryJ Urol. 1979 Oct; 122(4):508-11.

[10]. Pálfalvi L, Bôsze P, Ungár L.Vascular injuries in the surgical management of gynaecological malignancies. Eur J SurgOncol. 1993 Dec; 19(6):601-3.

[11]. Donat R Spahn, Vladimir Cerny, Timothy J Coats, et al Management of bleeding following major trauma: a European guideline Critical Care 2007, 11:414

[12]. Nordestgaard AG, Bodily KC, Osborne RW Jr, Buttorff JD Major vascular injuries during laparoscopic procedures Am J Surg. 1995 May;169(5):543-5.

[13]. Davidović LB, Sindjelić RB, Savić NB, Kostić DM, Svetković SD, Kuzmanović IB, Marković DM, Marković MM, Cinara IS, Maksimović ZL. Surgical treatment of abdominal tumours closely related to major blood vessels SrpArhCelokLek. 2008 MayJun; 136(5-6):241-7.

[14]. Volobuev NN, Zakhar'ian AL, Kalgin VV, Petruchek SV, RubanIuI.Iatrogenic injuries of blood vessels KlinKhir. 1994 ;(7):34-7. 